\title{
Oral low-dose dexamethasone for androgen-independent prostate cancer patients
}

\author{
AKIRA KOMIYA $^{1,2}$, MASAKI SHIMBO ${ }^{1,3}$, HIROYOSHI SUZUKI ${ }^{1}$, TAKASHI IMAMOTO ${ }^{1}$, TOMONORI KATO ${ }^{1}$, \\ SATOSHI FUKASAWA ${ }^{1}$, NAOTO KAMIYA ${ }^{1}$, YUKIO NAYA ${ }^{1}$, IKUO MORI ${ }^{3}$ and TOMOHIKO ICHIKAWA ${ }^{1}$ \\ ${ }^{1}$ Department of Urology, Chiba University Hospital, 1-8-1 Inohana, Chuo-ku, Chiba-shi, Chiba 260-8677; \\ ${ }^{2}$ Department of Urology, Graduate School of Medicine and Pharmaceutical Sciences for Research, \\ University of Toyama, 2630 Sugitani, Toyama-shi, Toyama 930-0194; ${ }^{3}$ Department of Urology, \\ Saiseikai Utsunomiya Hospital, 911-1 Takebayashi, Utsunomiya-shi, Tochigi 321-0974, Japan
}

Received January 27, 2009; Accepted June 23, 2009

DOI: $10.3892 /$ ol_00000013

\begin{abstract}
We retrospectively evaluated the outcome of oral low-dose dexamethasone (DXM) therapy for androgenindependent prostate cancer (AIPC). Between January 1999 and April 2006, 99 consecutive patients with AIPC were enrolled in this study. The median patient age was 70 years (range 46-86), and the median pretreatment prostate-specific antigen (PSA) level was $243 \mathrm{ng} / \mathrm{ml}$ (range 8.2-29600). Median follow-up was 41.9 months (range 11.4-170.4). Upon biochemical failure, patients were treated with oral low-dose DXM. A total of 40 of the 99 cases $(40.4 \%)$ showed a $\geq 50 \%$ decrease in serum PSA levels (PSA responders). Twenty-five cases (25.2\%) showed a $<50 \%$ decrease in PSA, and the remaining 34 cases (34.3\%) had increased PSA levels (PSA non-responders). The median PSA progression-free survival was 3.0 (range 0-27) and 8.0 months (range 2-27) for the entire cohort and PSA responders, respectively. The PSA responders had a significantly increased survival (median 30.1 months) compared to the non-responders (median 8.8 months, $\mathrm{P}<0.001$ ). Of the 34 patients who were under pain control for bone metastases before the administration of DXM, 23 (67.6\%) were able to discontinue the regular use of analgesics. The PSA responders also showed an increase in hemoglobin levels. The change in serum interleukin-6 levels was significantly associated with a response to DXM $(\mathrm{P}=0.0065)$. Severe adverse events of DXM were rare. Clinicopathological factors predicting the PSA response to DXM were age, time from initial androgen deprivation therapy to DXM and PSA velocity prior to DXM. In conclusion, oral low-dose DXM led to an acceptable PSA response in patients with AIPC. Thus, this therapy may be
\end{abstract}

Correspondence to: Dr Akira Komiya, Department of Urology, Graduate School of Medicine and Pharmaceutical Sciences for Research, University of Toyama, 2630 Sugitani, Toyama-shi, Toyama 930-0194, Japan

E-mail: komiya@med.u-toyama.ac.jp

Key words: dexamethasone, androgen, prostate cancer an effective and safe alternative for the treatment of AIPC, particularly for patients who are not favourable candidates for chemotherapy.

\section{Introduction}

Treatment for androgen-independent prostate cancer (AIPC) has been a challenge. During hormone therapy, prostate cancer initially responds well to androgen ablation; however, this response is gradually lost and the cancer becomes hormoneindependent. Some patients with AIPC maintain hormone dependency but are resistant to androgen ablation (1). In this state, low-dose dexamethasone (DXM) therapy is thought to be effective in addition to second- or third-line anti-androgens, or anti-androgen withdrawal.

Glucocorticoids are used in the management of AIPC. In addition to their anti-inflammatory effects, these agents exhibit antitumor activity. However, their therapeutic role in AIPC remains unclear (2,3). A few studies have demonstrated negative effects for prostate cancer suppression with higher doses of DXM $(4,5)$, or the antagonistic activity of DXM on prostate cancer cells with specific androgen receptor mutation (6). However, in most studies, DXM has exhibited an inhibitory effect on cell growth via intrinsic glucocorticoid receptors in androgen-independent prostate cancer cell lines such as PC-3 $(3,7)$ or DU145 (8). In the present study, we retrospectively evaluated the outcome of oral low-dose DXM therapy for AIPC in the largest cohort of patients studied thus far.

\section{Materials and methods}

We retrospectively studied 99 consecutive patients with prostate cancer who had been treated with hormone therapy (surgical castration or luteinizing hormone-releasing hormone agonist) and had shown biochemical failure [three consecutive increases in serum prostate-specific antigen (PSA) levels from the stabilized values]. These patients were treated either at Chiba University Hospital or Saiseikai Utsunomiya Hospital, and DXM therapy was started between January 1998 and April 2006. Patient characteristics are shown in Table I. Upon 
biochemical failure, patients were treated with oral low-dose DXM (initially $1.5 \mathrm{mg} / \mathrm{day}$, then reduced every 2 weeks to 0.5-1.0 mg/day). After 1995, in patients treated with surgical or medical castration plus anti-androgen (AA) therapy, AA withdrawal syndrome was assessed for at least 4-8 weeks after the cessation of AA and prior to DXM being initiated. For these patients, luteinizing hormone-releasing hormone agonist was not discontinued (9). Docetaxel was not used in any of the patients since it was only approved in 2008 in Japan. Serum PSA levels were determined with the Tandem-R PSA Assay (Hybritech, Inc., San Diego, CA). The PSA test was performed every 2 weeks in the first two months, and then every month after the 3rd month of DXM administration in AIPC patients. Serum levels of interleukin (IL)- 6 were measured in 18 patients before and after DXM administration using the chemiluminescent enzyme immunoassay (Cleia, SRL, Inc., Tokyo, Japan). The clinical effect of DXM was evaluated based on improvement of pain. Pain relief was defined as the ability of patients to discontinue the use of analgesics following DXM therapy. Pain scales were not used for assessment. Patients who showed $a \geq 50 \%$ decline in serum PSA levels were defined as PSA responders to DXM therapy. The remaining patients were defined as PSA non-responders. A decrease in PSA was confirmed with a second PSA level which was also $<50 \%$. Treatment failure was determined when patients showed three consecutive increases in PSA serum level. No routine bone or CT scans were performed during treatment.

Statistical analysis. Patient survival was analyzed by the Kaplan-Meier method. Statistical significance was examined using Student's t-test, Chi-square test, one-way analysis of variance (one-way ANOVA) and the log-rank test. Values are reported as the median or mean \pm SD. Multivariate analysis was performed using a Cox regression model. $\mathrm{P}<0.05$ was considered to be statistically significant (Stat-View program).

\section{Results}

\section{Clinical response to DXM therapy}

PSA response. Of the 99 cases, 40 (40.4\%) showed a $\geq 50 \%$ decrease in serum PSA levels. The PSA decrease was $<50 \%$ in 25 patients (25.3\%), and the other 34 cases (34.3\%) showed an increase in PSA levels. Eight $(8.1 \%)$ cases showed a $<4 \mathrm{ng} / \mathrm{ml}$ decrease in PSA levels. The PSA response was significantly associated with the time from initial hormone therapy to the start of DXM therapy, age at diagnosis of prostate cancer and the administration of DXM therapy and PSA velocity during the 3 months prior to DXM therapy (Table IIA) (10).

Improvement of pain. Low-dose DXM therapy was associated with improvement of cancer-related pain. Before administration of DXM therapy, 51 patients $(51.5 \%)$ had bone pain due to bone metastases. Thirty-four of these 51 used oral analgesics regularly for pain control. After the initiation of DXM therapy, 23 of these 34 patients (67.6\%) showed pain relief. Eight out of 11 were able to discontinue opioid analgesics. Pain relief was achieved irrespective of the PSA response (Table III).

Improvement of hemoglobin levels. Hemoglobin levels were compared before and after the administration of DXM, and
Table I. Characteristics of 99 prostate cancer patients undergoing low-dose dexamethasone therapy.

\begin{tabular}{lc}
\hline Characteristics & Values \\
\hline Median age at initial diagnosis & $70.0(46-86)$
\end{tabular}

(years)

Median age at DXM administration

$74 \pm 8.2(46-89)$

(years)

Median PSA before hormone therapy

$243.0(8.2-29600)$ (ng/ml)

Median PSA at DXM administration

$140.0(0.82-5911.0)$ (ng/ml)

Median time from initial PSA failure to

$15.0(1.0-56.8)$

administration of DXM (months)

Median time to administration of

DXM from the initiation of hormone therapy (months)

Median follow-up from the initial hormone therapy (months)

41.9 (11.4-207.3)

Clinical stage (unknown in 1 case) (n) $\mathrm{C}$

D1

D2

6

73

Gleason score (unknown in 5 cases) (n) 5

$6-5$

$7 \quad 26$

$8-19$

9228

$10-9$

EOD grade (unknown in 1 case) (n) 0

$1 \quad 11$

$2-21$

$3-33$

$4 \quad 6$

Treatment prior to low-dose DXM (n)

Castration only

Maximum androgen blockade

1

Number of prior hormonal agents ${ }^{\mathrm{a}}$

1

$2 \quad 41$

$3 \quad 37$

$4 \quad 2$

Prior chemotherapy

UFT

CDDP

1

Estramustine

15

Estramustine + etoposide

DXM, dexamethasone. EOD, extent of disease on initial bone scan (10). ${ }^{a} \mathrm{LH}-\mathrm{RH}$, luteinizing homone-releasing hormone was not discontinued. 
Table II. Parameters for prostate-specific antigen response and survival in the androgen-independent prostate cancer patients undergoing low-dose dexamethasone therapy.

A, Clinical parameters for PSA response

PSA response

\section{Clinical parameters}

Clinical stage $(n=99)$

C

D

Gleason score $(n=94)$

2-7

8-10

Interval to DXM (years) $(\mathrm{n}=99)$

$\geq 3$

$<3$

Anti-androgen withdrawal syndrome ( $\mathrm{n}=92)$

$+$

Age at diagnosis $(n=99)$

Mean \pm SD

Range

Median

PSA at diagnosis $(\mathrm{ng} / \mathrm{ml})(\mathrm{n}=99)$

Mean \pm SD

Range

Median

Age at administration of DXM ( $=99)$

Mean \pm SD

Range

Median

PSA at administration of DXM $(n=99)$

Mean \pm SD
Range
Median

PSA velocity (ng/ml/month) in 3 months before start of DXM (n=66)

Mean \pm SD
Range
Median

PSA doubling time (month) 3 months before start of DXM ( $n=66)$

\section{Mean \pm SD}

Range

Median

EOD $(n=98)$

$0-2$

3-4

Bone pain

Improved

Unimproved

Hemoglobin before start of DXM (g/dl) $(\mathrm{n}=99)$

Mean \pm SD
Range
Median

$\begin{array}{lll}\mathrm{PR}+\mathrm{CR} & \mathrm{NC}+\mathrm{PD} & \text { P-value }\end{array}$

n.s.

$31 \quad 49$

$17 \quad 20 \quad$ n.s.

$19 \quad 37$

$22 \quad 20$

$18 \quad 39$

$7 \quad 14$

n.s.

$30 \quad 41$

$\begin{array}{cc}67.8 \pm 7.7 & 71.3 \pm 6.9 \\ 46-85 & 53-86 \\ 68 & 72\end{array}$

0.0196

$1392.3 \pm 436.6$

$1288.8 \pm 543.6$

n.s.

27.6-12490.0

8.2-29600.0

211.0
$71.2 \pm 8.2$
47-88
72

$74.6 \pm 7.5$

54-89

75

$271.7 \pm 452.4$
$10.7-2110.0$
106.0

$419.6 \pm 849.9$

0.8-5911.0

140.0

$\begin{array}{ccc}35.8 \pm 76.4 & 117.3 \pm 262.5 & 0.0272 \\ 1.8-382.3 & -2.0-1496.6 & \\ 12.0 & 23.0 & \\ & & \\ 2.5 \pm 1.9 & 2.5 \pm 2.9 & \text { n.s. } \\ 0.6-8.7 & -0.8-14.1 & \\ 2.0 & 1.5 & \\ & & \\ 25 & 34 & \\ 15 & 24 & \\ & & \\ 20 & 23 & 0.0552 \\ 1 & 7 & \\ 11.9 \pm 1.71 & & \\ 7.7-14.8 & 11.7 \pm 1.7 & \\ 12.3 & 7.2-16.3 & \end{array}$


Table II. Continued.

\begin{tabular}{|c|c|c|c|c|}
\hline Prognostic parameters & Improved in & $95 \%$ confidence interval & Relative hazards ratio & P-value \\
\hline $\begin{array}{l}\text { PSA response } \\
(\geq 50 \%,<50 \% \text { decrease })\end{array}$ & $\geq 50 \%$ decrease & $0.16006-0.75542$ & 0.34770 & 0.0076 \\
\hline PSA velocity (ng/ml/month) & Lower & 0.99784-0.99993 & 0.99889 & 0.0373 \\
\hline $\begin{array}{l}\text { Interval to DXM }{ }^{\mathrm{a}} \\
\text { (mean } 38.2 \text { months) }\end{array}$ & $>38.2$ months & $0.19571-0.95283$ & 0.43183 & 0.0375 \\
\hline EOD & Lower & $0.47123-0.83882$ & 0.62900 & 0.0016 \\
\hline
\end{tabular}

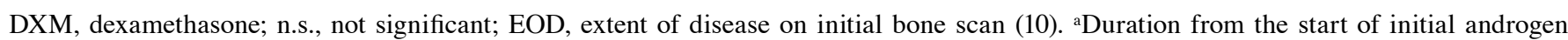
deprivation to the administration of DXM.

Table III. Pain relief after DXM therapy.

\begin{tabular}{|c|c|c|c|c|}
\hline Analgesics & PSA response & $\mathrm{n}$ & $\begin{array}{l}\text { Discontinuation } \\
\text { of analgesics }\end{array}$ & Pain relief $(\%)$ \\
\hline \multirow[t]{3}{*}{ Non-steroidal anti-inflammatory drugs } & $\geq 50 \%$ decrease & 12 & 9 & 75 \\
\hline & $<50 \%$ decrease & 11 & 6 & 55 \\
\hline & Total & 23 & 15 & 65 \\
\hline \multirow[t]{3}{*}{ Opioid analgesics \pm non-steroidal anti-inflammatory drugs } & $\geq 50 \%$ decrease & 4 & 3 & 75 \\
\hline & $<50 \%$ decrease & 7 & 5 & 71 \\
\hline & Total & 11 & 8 & 73 \\
\hline Total & & 34 & 23 & 68 \\
\hline
\end{tabular}

levels increased significantly in PSA responders (median, average $\pm \mathrm{SD})(0.9,0.8 \pm 1.0 \mathrm{~g} / \mathrm{dl} ; \mathrm{P}<0.0001)$, whereas no change was observed in the PSA non-responders $(0.2,-0.16 \pm 1.57 \mathrm{~g} / \mathrm{dl}$; not significant).

Survival. The median progression-free survival was 3 months for the entire cohort, as well as for patients with a PSA decline of $<50 \%$. In addition, the median progression-free survival was 7 months for patients with a PSA decline of $\geq 50 \%$ (but not $<4.0 \mathrm{ng} / \mathrm{ml})$, and 8.5 months for those with a PSA of $<4.0 \mathrm{ng} /$ $\mathrm{ml}(\mathrm{P}<0.0001)$.

In Fig. 1, curve (a) shows the cause-specific survival of the 99 cases who underwent oral low-dose DXM therapy. Median survival was 12.0 months (range 0.7-58.2). Curves (b-d) show the cause-specific survival according to the response to lowdose DXM therapy. When patients were stratified by response, a significant difference in survival was observed among patient groups ( $\mathrm{P}=0.0004$, PSA decrease $\geq 50 \%$ versus PSA decrease $<50 \%$; $\mathrm{P}<0.0001$, PSA decrease $\geq 50 \%$ versus PSA increase). The median cause-specific survival was $30.1,9.0$ and 6.9 months in patients with a PSA decrease of $\geq 50 \%,<50 \%$ and a PSA increase, respectively. Differences in survival between the latter two groups were not significant. When the latter two groups (PSA non-responders) were combined, the median cause-specific survival was 8.8 months, which was poorer than that of the PSA responders $(\mathrm{P}<0.001)$.

Table IIB shows the multivariate analysis of cause-specific survival in patients who underwent DXM therapy. Clinical parameters shown in Table IIA were assessed in the prognostic model. The PSA response to DXM, the PSA velocity 3 months before the administration of DXM, the interval from the initiation of hormone therapy to the administration of DXM, and the extent of disease (EOD) score of bone metastasis at initial diagnosis were independent prognostic factors. Alkaline phosphatase was not assessed in this study. In addition, neither the hemoglobin levels nor the number of prior therapies were considered to be prognostic variables (data not shown).

Changes in serum interleukin-6 levels. We measured the serum levels of IL- 6 before and after DXM in 18 patients. The patients had elevated serum IL-6 levels ( $>4.0 \mathrm{pg} / \mathrm{ml})$ (cut-off). As shown in Table IV, changes in serum IL-6 levels were significantly associated with response to DXM in AIPC patients.

Adverse events. A total of 68 of the $99(68.7 \%)$ cases did not experience any adverse effects due to DXM. Although a 


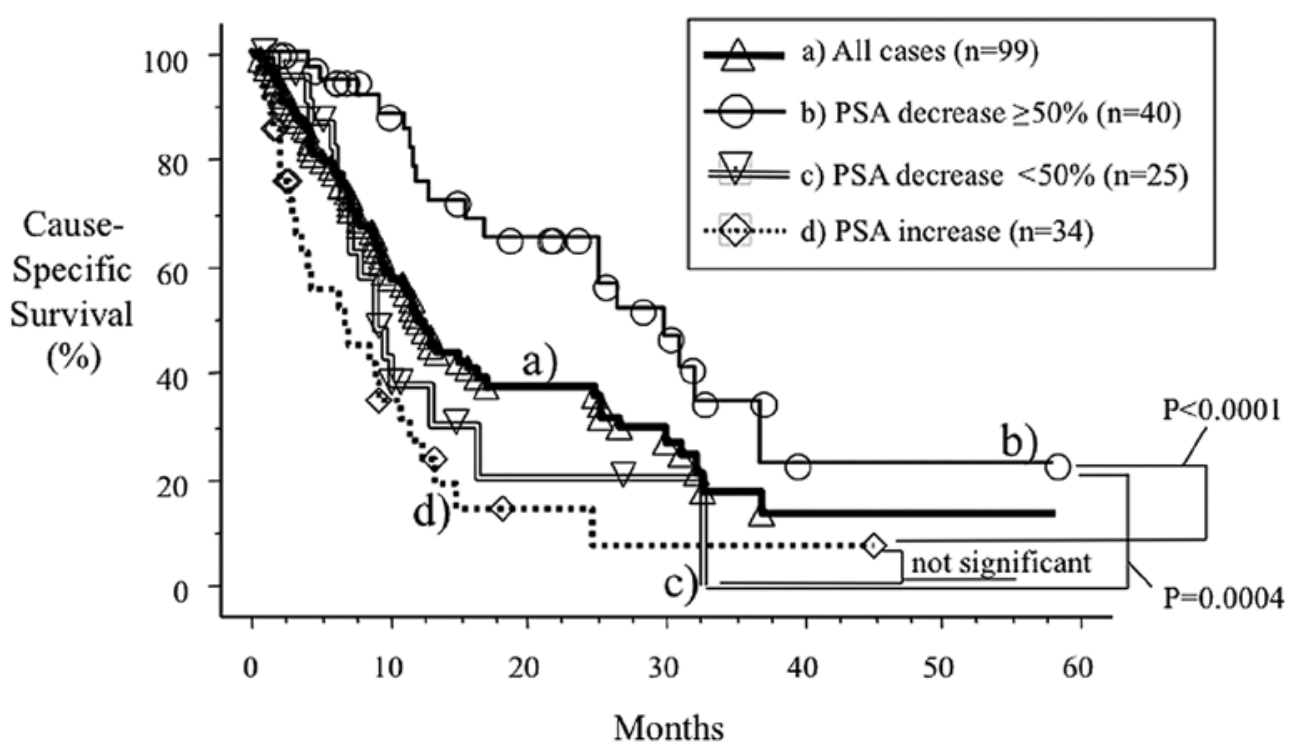

Figure 1. Cause-specific survival after low-dose dexamethasone (DXM) therapy. (a) For all 99 cases; (b-d) classified according to the PSA response.

Table IV. Relationship between response to dexamethasone therapy and change in serum interleukin-6 levels in 18 patients.

\begin{tabular}{lccr}
\hline & IL-6 normalized (n) & IL-6 not normalized (n) & Total (n) \\
\hline DXM responder & 10 & 3 & 13 \\
DXM non-responder & 0 & 5 & 5 \\
\hline
\end{tabular}

IL-6, interleukin 6. All of the 18 patients had elevated serum IL-6 levels.

Table V. Comparison of efficacy of glucocorticoids for androgen-independent prostate cancer.

\begin{tabular}{|c|c|c|c|c|c|c|}
\hline Authors, year (reference) & $\mathrm{n}$ & Glucocorticoids & Dose (mg) & $\begin{array}{c}\text { Median time to } \\
\text { progression (months) }\end{array}$ & Response (\%) & Response (\%) \\
\hline Kelly et al, 1995 (23) & 30 & Hydrocortisone & 40 & 4 & 20 & 17/111 (15) \\
\hline Kantoff et al, 1999 (24) & 81 & Hydrocortisone & 40 & 2 & 14 & \\
\hline Tannock et al, 1989 (25) & 37 & Prednisone & $7.5-10$ & Not indicated & 38 & $28 / 81(35)$ \\
\hline Sartor et al, 1998 (26) & 29 & Prednisone & 10 & 2 & 34 & \\
\hline Fuse et al, 2006 (27) & 15 & Prednisolone & 10 & 3.5 (mean) & 27 & \\
\hline Nishiyama et al, 1998 (28) & 7 & Dexamethasone & $1.5 \rightarrow 0.5$ & 9 & 57 & $71 / 143(50)$ \\
\hline Nishimura et al, 2000 (3) & 37 & Dexamethasone & $1.0 \rightarrow 2.0$ & 9 & 62 & \\
\hline Present study, 2008 & 99 & Dexamethasone & $1.5 \rightarrow 0.5-1.0$ & 7 & 40 & \\
\hline
\end{tabular}

routine assessment of osteoporosis, steroid myopathy or skin ecchymosis was not performed, these adverse events did not warrant discontinuation of the DXM treatment. The most frequent adverse events were moon face $(n=10,11.1 \%)$, gastric ulcer $(n=6,6.1 \%)$, and fracture $(n=5,5.1 \%)$. We found 2 cases of body weight gain and hot flash. Cataracts were present in 1 case, hypertension in 1, edema in 1 and depression in 1 . These cases were grades 1-2. Only one grade 3 gastric ulcer occurred; based on the National Cancer Institute - Common
Toxicity Criteria, version 2.0. Neither grade 4 events nor treatment-related deaths occurred in this cohort.

\section{Discussion}

In the present study, we retrospectively examined the efficacy of low-dose DXM therapy in the management of AIPC in a larger number of patients as compared with previous studies. Important characteristics of low-dose DXM include i) a relatively 
high response rate, ii) efficacy in the improvement of subjective symptoms, iii) the ability of DXM to be administered orally (helps maintain quality of life) and iv) lack of severe adverse effects. The PSA response to DXM was a strong independent prognostic factor. Younger patients with a longer history of hormone therapy and with slow-growing cancer appear to be favourable candidates for DXM therapy.

In previously reported outcomes of glucocorticoids for AIPC $(3,11)$, the PSA response rate $(\geq 50 \%$ decrease in PSA) ranged from 44 to $68 \%$, and the median time to progression was approximately 9 months. Our results were comparable to these findings. The response rate itself was not significantly lower than that noted with other cytotoxic agents used for AIPC. Safety was achieved, although 5 patients (5.1\%) experienced a fracture, which, in addition to DXM, may have been due to a relatively longer period of androgen deprivation therapy known to cause osteoporosis. Routine assessment of osteoporosis and its treatment using bisphosphonate such as zoledronic acid are recommended, although neither were performed in this study (12). Prophylactic anti-ulcerative agents should be prescribed simultaneously with DXM to prevent gastric ulcers as this adverse effect occurred relatively frequently in this study (6/99 patients, 6.1\%), albeit in only one grade 3 case.

Even though docetaxel has become one of the most frequently used options for the management of AIPC in Western countries, our findings indicate that low-dose DXM is an important treatment option for urologists. This treatment is suitable particularly for patients who are not favourable candidates for cytotoxic agents.

Suppression of adrenal androgen secretion by DXM is believed to have a significant anti-tumor effect against prostate cancer. Glucocorticoids can inhibit prostate cancer cell growth by modulating cellular growth factors (11). Our previous report (13) demonstrated that serum levels of adrenal androgens such as dehydroepiandrosterone, dehydroepiandrosterone sulfate or androstendione were suppressed by DXM therapy irrespective of the response to this treatment.

Akakura et al (13) suggested that the significant suppression of IL- 6 is another possible mechanism of dexamethasone action. IL-6 is known to be suppressed by glucocorticoids (6) and to stimulate the growth of prostate cancer cell lines through glucocorticoid receptors in an androgen-independent manner (3,14-17). In addition, IL-6 has been shown to activate the androgen receptor through a STAT3-dependent pathway (17-19). In this study, changes in serum IL-6 levels were significantly associated with the response to DXM in AIPC patients. Therefore, suppression of IL-6 has been accepted as a significant mechanism of DXM activity in AIPC.

The recent position of glucocorticoids in the management of prostate cancer is mainly found in the control arms or is for prophylactic use for adverse events in clinical trials for AIPC, in which prednisone is most frequently administered $(20,21)$. On the other hand, results for DXM monotherapy have been less documented. DXM is thought to be a more potent agent than prednisone/prednisolone or hydrocortisone because of its stronger glucocorticoid activity and lower mineralocorticoid activity (3). In clinical practice, the PSA response rate for AIPC was $14-20 \%$ for hydrocortisone (40 mg/day), $27-38 \%$ for prednisone/prednisolone (7.5-10 $\mathrm{mg} /$ day) and 40-62\% for dexamethasone $(0.5-1.5 \mathrm{mg} /$ day) (Table V) $(3,11,13)$.
Relatively higher doses of dexamethasone are currently used in an intermittent manner to reduce the hypersensitivity reactions and fluid retention associated with docetaxel $(20,21)$. It was reported that DXM does not significantly contribute to the response rate of docetaxel and estramustine in AIPC (5), and that intermittent DXM results in a less profound suppression of adrenal androgens. Glucocorticoid receptors are generally down-regulated by glucocorticoids in a dose-dependent manner (22). Therefore, low-dose DXM is a reasonable choice of therapy for a longer duration of response as well as for reducing adverse events.

In conclusion, low-dose DXM therapy in the treatment of AIPC is well tolerated and safe, and may be one of the acceptable options in the management of AIPC, particularly for patients who are not favourable candidates for cytotoxic agents or in countries where docetaxel is not available.

\section{References}

1. Scher HI, Steineck G and Kelly WK: Hormone-refractory (D3) prostate cancer: refining the concept. Urology 46: 142-148, 1995.

2. Fakih M, Johnson CS and Trump DL: Glucocorticoids and treatment of prostate cancer: a preclinical and clinical review. Urology 60: 553-561, 2002.

3. Nishimura K, Nonomura N, Yasunaga Y, et al: Low doses of oral dexamethasone for hormone-refractory prostate carcinoma. Cancer 89: 2570-2576, 2000.

4. Zhang C, Mattern J, Haferkamp A, et al: Corticosteroid-induced chemotherapy resistance in urological cancers. Cancer Biol Ther 5: 59-64, 2006.

5. Weitzman AL, Shelton G, Zuech N, et al: Dexamethasone does not significantly contribute to the response rate of docetaxel and estramustine in androgen-independent prostate cancer. J Urol 163: 834-837, 2000.

6. Chang CY, Walther PJ and McDonnell DP: Glucocorticoids manifest androgenic activity in a cell line derived from a metastatic prostate cancer. Cancer Res 61: 8712-8717, 2001.

7. Reyes-Moreno C, Frenette G, Boulanger J, Lavergne E, Govindan MV and Koutsilieris M: Mediation of glucocorticoid receptor function by transforming growth factor beta I expression in human PC-3 prostate cancer cells. Prostate 26: 260-269, 1995.

8. Gao QZ, Lu JJ, Liu ZD, Zhang $\mathrm{H}$, Wang SM and Xu H: Dexamethasone suppresses DU145 cell proliferation and cell cycle through inhibition of the extracellular signal-regulated kinase 1/2 pathway and cyclin D1 expression. Asian J Androl 10: 635-641, 2008.

9. Akakura K, Akimoto S, Ohki T and Shimazaki J: Antiandrogen withdrawal syndrome in prostate cancer after treatment with steroidal antiandrogen chlormadinone acetate. Urology 45: 700-705, 1995.

10. Soloway MS, Hardeman SW, Hickey D, et al: Stratification of patients with metastatic prostate cancer based on extent of disease on initial bone scan. Cancer 61: 195-202, 1988.

11. Lam JS, Leppert JT, Vemulapalli SN, Shvarts O and Belldegrun AS: Secondary hormonal therapy for advanced prostate cancer. J Urol 175: 27-34, 2006.

12. Saad F, Gleason DM, Murray R, et al: Long-term efficacy of zoledronic acid for the prevention of skeletal complications in patients with metastatic hormone-refractory prostate cancer. J Natl Cancer Inst 96: 879-882, 2004.

13. Akakura K, Suzuki H, Ueda T, et al: Possible mechanism of dexamethasone therapy for prostate cancer: suppression of circulating level of interleukin-6. Prostate 56: 106-109, 2003.

14. Okamoto $M$, Lee $C$ and Oyasu R: Interleukin- 6 as a paracrine and autocrine growth factor in human prostatic carcinoma cells in vitro. Cancer Res 57: 141-146, 1997.

15. Chung TD, Yu JJ, Spiotto MT, Bartkowski M and Simons JW: Characterization of the role of IL-6 in the progression of prostate cancer. Prostate 38: 199-207, 1999.

16. Lou W, Ni Z, Dyer K, Tweardy DJ and Gao AC: Interleukin-6 induces prostate cancer cell growth accompanied by activation of stat3 signaling pathway. Prostate 42: 239-242, 2000. 
17. Hobisch A, Eder IE, Putz T, et al: Interleukin-6 regulates prostate-specific protein expression in prostate carcinoma cells by activation of the androgen receptor. Cancer Res 58: 4640-4645, 1998.

18. Chen T, Wang LH and Farrar WL: Interleukin 6 activates androgen receptor-mediated gene expression through a signal transducer and activator of transcription 3-dependent pathway in $\mathrm{LNCaP}$ prostate cancer cells. Cancer Res 60: 2132-2135, 2000.

19. Ueda T, Bruchovsky N and Sadar MD: Activation of the androgen receptor N-terminal domain by interleukin-6 via MAPK and STAT3 signal transduction pathways. J Biol Chem 277: 7076-7085, 2002.

20. Tannock IF, de Wit R, Berry WR, et al: Docetaxel plus prednisone or mitoxantrone plus prednisone for advanced prostate cancer. $\mathrm{N}$ Engl J Med 351: 1502-1512, 2004.

21. Petrylak DP, Tangen CM, Hussain MH, et al: Docetaxel and estramustine compared with mitoxantrone and prednisone for advanced refractory prostate cancer. $\mathrm{N}$ Engl $\mathrm{J}$ Med 351: 1513-1520, 2004.

22. Shimojo M, Hiroi N, Yakushiji F, Ueshiba H, Yamaguchi $N$ and Miyachi Y: Differences in down-regulation of glucocorticoid receptor mRNA by cortisol, prednisolone and dexamethasone in HeLa cells. Endocr J 42: 629-636, 1995.
23. Kelly WK, Curley T, Leibretz C, Dnistrian A, Schwartz M and Scher HI: Prospective evaluation of hydrocortisone and suramin in patients with androgen-independent prostate cancer. J Clin Oncol 13: 2208-2213, 1995.

24. Kantoff PW, Halabi S, Conaway M, et al: Hydrocortisone with or without mitoxantrone in men with hormone-refractory prostate cancer: results of the cancer and leukemia group B 9182 study. J Clin Oncol 17: 2506-2513, 1999.

25. Tannock I, Gospodarowicz M, Meakin W, Panzarella T, Stewart L and Rider W: Treatment of metastatic prostatic cancer with low-dose prednisone: evaluation of pain and quality of life as pragmatic indices of response. J Clin Oncol 7: 590-597, 1989.

26. Sartor O, Weinberger M, Moore A, Li A and Figg WD: Effect of prednisone on prostate-specific antigen in patients with hormonerefractory prostate cancer. Urology 52: 252-256, 1998.

27. Fuse H, Nozaki T, Fujiuchi Y, Mizuno I, Nagakawa O and Okumura A: Treatment with prednisolone of hormone-refractory prostate cancer. Arch Androl 52: 35-38, 2006.

28. Nishiyama T and Terunuma M:Hormone/antihormone withdrawal and dexamethasone for hormone-refractory prostate cancer. Int J Urol 5: 44-47, 1998. 